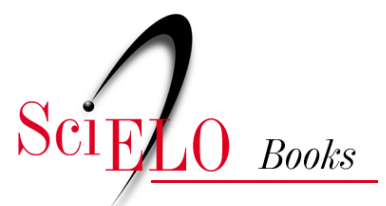

\title{
Capítulo 4. Cidades novas e o profissional
}

\author{
Ricardo Trevisan
}

\section{SciELO Books / SciELO Livros / SciELO Libros}

TREVISA, R. Cidades novas e o profissional. In: Cidades novas [online]. Brasília: Editora UnB, 2020, pp. 167-187. Pesquisa, inovação \& ousadia series. ISBN: 978-65-5846-158-6.

https://doi.org/10.7476/9786558461586.0009.

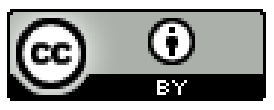

All the contents of this work, except where otherwise noted, is licensed under a $\underline{\text { Creative }}$ Commons Attribution 4.0 International license.

Todo o conteúdo deste trabalho, exceto quando houver ressalva, é publicado sob a licença Creative Commons Atribição 4.0.

Todo el contenido de esta obra, excepto donde se indique lo contrario, está bajo licencia de la licencia Creative Commons Reconocimento 4.0. 


\section{Cidades novas e o profissional}

Quarta parada: Águas de São Pedro, São Paulo.

Para relaxamento momentâneo, convido os leitores a um breve passeio pela estância hidromineral de Águas de São Pedro (ASP), uma pacata cidade próxima a Piracicaba, no interior do estado de São Paulo. Uma CN balneária projetada e construída a partir do final da década de 1930, referência nacional pela sua excelente qualidade de vida (BUCHALLA, 2000). Fruto capitalista de uma pequena elite, esse balneário atrai turistas de várias partes do Brasil, que buscam fugir do cotidiano estressante das grandes cidades, revitalizando suas energias. Atraídos são pela qualidade terapêutica das águas minerais, que jorram de suas três principais fontes - Gioconda, Juventude e Almeida Salles -, pela paisagem campestre e pela tranquilidade oferecida no ambiente do menor município do país - com 3,5 km² de área urbana, sem presença de área rural.

Mas nem sempre foi assim. As terras onde esse núcleo urbano se encontra configuravam-se, em fins da década de 1920, como vastos campos de plantação de café, que, nessa época, já apresentavam sinais de enfraquecimento tanto por problemas na economia de exportação quanto pelo desgaste sofrido pelo solo com esse tipo de produção. Impulsionada pela busca de petróleo, como um dos produtos a substituir o café no contexto econômico nacional, a região do município de São Pedro sofreu as primeiras prospecções tendo, porém, como resultado, apenas a obtenção de águas minerais em grande quantidade (RODRIGUES, 1985).

A ideia de transformar a área desses poços em balneários medicinais e, posteriormente, numa cidade para vilegiatura coube a uma sociedade formada por empresários e donos de terras locais, da capital paulista e da cidade de Santos, liderados pelos irmãos Antônio Joaquim de Moura Andrade e Octávio de Moura Andrade. A criação, 


\section{Cidades novas}

em 1935, da empresa Águas Sulphídricas e Thermaes de São Pedro S/A por esse restrito grupo representava um modo de aplicar o grande excedente de capital gerado no auge da economia cafeeira em novas oportunidades seguramente rentáveis.

Figura 12: Águas de São Pedro

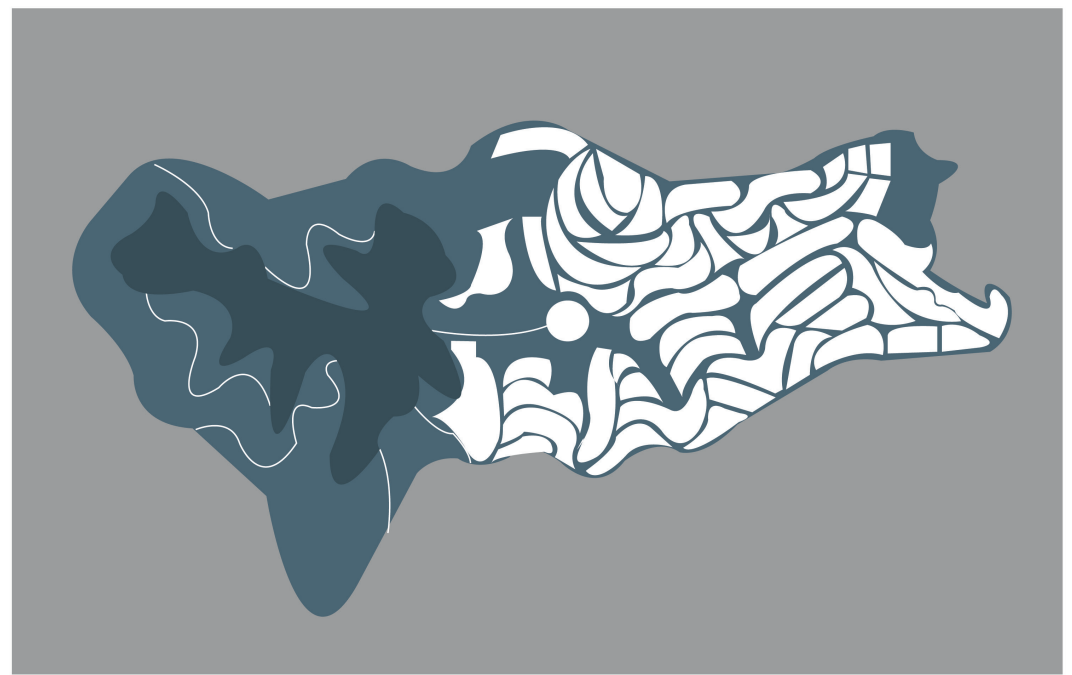

O projeto da cidade apresentou duas etapas: a primeira direcionada à construção do complexo do balneário - “um hotel de luxo, tipo ‘palace’ [não executado]; um grande hotel tipo intermediário [...]; um edifício para termas-sanatorio, onde estão localizados: o balneário, as instalações de fisio e mechano-therapia [...]; um cassino, duas colônias de férias, um restaurante e as demais instalações indispensáveis (buvette, piscinas, quadras de tenis, etc.)” (ÁGUAS SULPHÍDRICAS E THERMAES DE SÃO PEDRO S/A, 1940, s.p.) -, compreendendo uma área de aproximadamente 147 hectares (52\% do total); e a segunda voltada à construção de uma cidade (urbanização e loteamento), com 135 hectares.

A primeira etapa ficou a cargo do engenheiro civil Luiz Camerlingo (19081938) e de outros profissionais da área de pesquisas científicas e de paisagismo, como o médico Jorge Aguiar Pupo, o engenheiro químico Francisco João Maffei 
e o botânico suíço Julius Borchard; a segunda foi realizada pelo engenheiro civil Jorge de Macedo Vieira, auxiliado por Francisco Saturnino Rodrigues de Brito Filho, do Escritório Técnico Saturnino de Brito.

O engenheiro Luiz Camerlingo, ${ }^{1}$ entre 1936 e 1938, foi responsável pelo projeto do Grande Hotel São Pedro e pelo programa de necessidades da CN. Um programa escrito em artigos sequenciados no Jornal Caldas de São Pedro (entre setembro e outubro de 1937), com o título: "Como um architecto e urbanista deve orientar um programma para a organização de um projecto d'uma cidade de aguas e estancia de repouso". Nesse tratado, encontramos desde os cuidados mais gerais até os mais específicos que o construtor deve ter ao realizar tal empreendimento. A riqueza de detalhamentos nos indica a total sintonia entre Luiz Camerlingo e as principais ideias urbanísticas de seu tempo. A participação de Camerlingo, todavia, extrapolou a elaboração desse programa. Em 1936, com o apoio da empresa, o engenheiro foi responsável pela escolha do local onde seria implantada a estância (VIEIRA, 1939), projetando sobre ela o Grande Hotel, estrategicamente posicionado. Concomitantemente, iniciaram-se as obras de construção do aeroporto e do reflorestamento da nascente do córrego Bebedouro, ao lado do hotel.

Quanto ao plano urbanístico, caso tenha havido qualquer possibilidade de Camerlingo ter sido escolhido para ser dele o autor, foi prejudicada em fevereiro de 1938: a aeronave que o engenheiro pilotava caiu quando fazia o trajeto Rio Claro - São Pedro, tirando sua vida aos 30 anos de idade.

Com a morte de Camerlingo, o engenheiro-arquiteto Dacio Aguiar de Moraes assumiu a fase de acabamento do Grande Hotel e também gerenciou, ao lado do arquiteto Jaime Campello Fonseca Rodrigues, as maiores obras arquitetônicas realizadas posteriormente.

\footnotetext{
1 Paulista de Laranjal (1908), Camerlingo diplomou-se em engenharia civil e foi dono de um escritório de construção na capital paulista, onde participou do concurso para a construção do novo Viaduto do Chá, classificando-se em segundo lugar. Como curiosidade, Camerlingo tinha por hobby a aviação, assim como os empreendedores irmãos Moura Andrade, apresentando até brevet de piloto internacional.
} 
Simultaneamente, para o sucesso do empreendimento como estância hidroterápica, era necessário comprovar as reais virtudes das águas subterrâneas - identificando seus elementos químicos - e como incorporá-las a tratamentos de doenças diversas. A primeira tarefa foi repassada ao Instituto de Pesquisa e Tecnologia (IPT), anexo à Escola Politécnica de São Paulo. O responsável por pesquisar as amostras, designado pelo IPT, foi o diretor do departamento de Química, professor Francisco João Maffei (1899-1968). Durante determinado tempo, Maffei manteve seu laboratório na própria estância, de onde emitiu seus relatórios.

A segunda tarefa ficou a cargo dos médicos Jorge Aguiar Pupo, José Bonifácio de Almeida Salles e Franklin de Moura Campos. Recebendo os relatórios elaborados por Maffei, os professores da Faculdade de Medicina de São Paulo e seguidores da Hidrologia Médica - em voga na época - elaboraram laudos especificando os métodos de utilização das águas de acordo com cada moléstia.

Visando a obter lucros também com a industrialização das águas minerais que vinham do solo, exportando-as como água medicinal ou como refrigerante para outras cidades e estados, os irmãos Moura Andrade contrataram os serviços da Companhia Siemens e da Casa Lohner para construir e fornecer máquinas e materiais mecânicos necessários ao processamento e engarrafamento das referidas águas.

Para o projeto paisagístico do balneário, buscando recuperar o terreno devastado por anos de cultura cafeeira, os Moura Andrade recorreram ao Viveiro Manequinho Lopes (Ibirapuera). Este incumbiu o botânico suíço Julius Borchard, recém-chegado ao país, para desenvolver o projeto paisagístico. Mas essa área também contou com a participação do professor Edmundo Navarro de Andrade (1881-1941), da Escola Superior de Agronomia Luiz de Queiroz (Piracicaba). Tendo acabado de elaborar o projeto para o Horto Florestal da cidade de Rio Claro, Navarro foi responsável por comandar o plantio dos milhares de pés de eucalipto no Parque Municipal da estância.

Como suporte às obras e ao consumo interno do hotel e, posteriormente, da futura cidade, também foi pensada a elaboração de instalações subsidiárias. A autossustentabilidade do núcleo começou a se concretizar pela construção de modestos 
galpões nos arredores do balneário para produzir tijolos, telhas, madeiramento, ladrilhos, peças em granito, ferramentas, mobílias como também fornecer alimentos (laticínios, frutas, verduras, carne suína e bovina etc.).

Criando-se as bases necessárias para o funcionamento primário da estância, foi iniciada, em 1938, a segunda etapa do projeto, voltada à urbanização e ao loteamento da CN. O núcleo teria capacidade para atender a uma população de 10 mil habitantes atualmente conta com 2,7 mil moradores, chegando a 34 mil em feriados prolongados.

Jorge de Macedo Vieira (1894-1978)² e sua equipe instalaram base por três anos numa casa na antiga sede da fazenda onde se construía a cidade. Dali, o engenheiro civil comandou o trabalho de levantamento de curvas de nível, metro por metro, de toda a área, para poder fazer o projeto da cidade - após a morte de Camerlingo. Só o trabalho de medição demorou dois anos aproximadamente para ser concluído. Após o levantamento, Jorge passou à parte específica do projeto e à sua execução.

Para isso, contou com o auxílio do Escritório Técnico Saturnino de Brito, responsável pelos estudos de viabilização e execução das infraestruturas de saneamento. Embora tenha sido o engenheiro civil e de minas Francisco Saturnino Rodrigues de Brito Filho (1899-1977) o responsável pela obra de saneamento da estância hidromineral de ASP, os preceitos nela aplicados decorrem do legado deixado por seu pai, o engenheiro sanitarista Saturnino de Brito (projetista do plano de expansão de Santos).

Como partido projetual para ASP, o engenheiro Vieira baseou-se nas experiências para loteamentos em áreas acidentadas que já havia realizado em outras

2 Formou-se engenheiro civil, em 1918, pela Escola Politécnica de São Paulo. Entre 1917 e 1919, estagiou no escritório de planejamento da Companhia City. Essa experiência possibilitou-lhe o contato com as ideias e os trabalhos do inglês Richard Barry Parker (projetista da primeira cidade-jardim: Letchworth, Inglaterra) e, principalmente, ter conhecimento sobre os princípios howardianos da cidade-jardim. Em suas obras posteriores a esse período, nota-se a forte influência que esse ideário exerceu na formação de seu repertório teórico. Exemplos dessa assimilação podem ser verificados nos bairros por ele projetados para as cidades de Campinas, Atibaia, Campos do Jordão e São Paulo, e nos planos urbanos para as CNs de Águas de São Pedro (1937), Maringá (1945), Cidade Balneária de Pontal do Sul (1951) e Cianorte (1955). Em ASP, é possível analisar a integração feita por Vieira entre o urbanismo cidade-jardim - forma - e as especificidades necessárias a uma cidade balneária - função. 
cidades, implantando o futuro loteamento de forma a adequar-se à área determinada. Do mesmo modo, Vieira e Brito Filho usufruíram de todos os recursos urbanísticos - densa arborização, vielas sanitárias como passagens para pedestres, ruas sinuosas de aclive suave, esquinas como pequenas praças, talvegues destacados por sua área verde, cruzamentos principais com rotatórias, larga avenida principal de entrada etc. - para a elaboração de um plano singular.

Consciente das funções que a cidade iria ter, Vieira apenas se preocupou com a largura ampla das vias no eixo central (32 metros), possibilitando acesso fácil ao fluxo de veículos que se dirigiriam ao balneário, ao parque, ao cassino e ao hotel. Tendo como parâmetro a distribuição do trânsito feita para outras estâncias projetadas, achou coerente sua proposta como parkway, enquanto as demais vias ficaram com larguras menores (11 metros), economizando despesas públicas com pavimentação, limpeza, drenagem e conservação.

Do traçado viário, surgiram 55 quadras, sendo 13 destinadas aos estabelecimentos comerciais e aos equipamentos públicos e as restantes, às áreas residenciais. Se o planejamento destacou a maioria das quadras como residenciais, as quadras comerciais, pela necessidade de estarem presentes em locais com maior fluxo de pessoas, foram setorizadas numa das melhores áreas da cidade, entre o Parque Municipal e a Praça Central (rótula de 96 metros de diâmetro).

O loteamento residencial dividiu-se em três tipos diferentes. A primeira área, com posição estratégica próxima ao balneário e ao parque, foi especialmente traçada, diferenciando-se das demais pela faixa única de lotes nas quadras com aberturas para duas vias. As outras duas regiões foram separadas pelo córrego Bebedouro, configurando-se a localizada a sudeste como um setor ocupado principalmente por chalés e casas de veraneio; e a da margem nordeste, devido à sua ocupação por casas operárias - construídas, alugadas ou arrendadas pela empresa para os operários que ajudaram a erguer a cidade -, ficou ocupada em grande parte pelos habitantes fixos da cidade, geralmente de classes média e média baixa. 
A grande dimensão do empreendimento necessitava, entretanto, de mão de obra operária para torná-la realidade. Para a empresa, isso não foi um empecilho. Recém-liberados do campo pela crise na lavoura cafeeira, os trabalhadores locais constituíam-se numa mão de obra abundante e barata (RODRIGUES, 1985). Numericamente, os empreendedores da estância contaram com quatrocentos trabalhadores presentes nas produções fabris e na construção civil.

Em 10 de abril de 1940, o presidente Getúlio Vargas concedeu à estância, mediante um decreto-lei daquele ano, o grau de "estância hidro-mineral e climática, de tratamento e repouso”, também qualificada como “Águas de São Pedro”.

Desse modo, o espírito capitalista dos empreendedores, buscando planejar o balneário não somente pelas necessidades imediatas, mas também pelas de longo prazo, possibilitou criar uma cidade estruturada de forma minuciosa em todos os seus aspectos. Além de contratar os serviços de importantes engenheiros da época (Jorge de Macedo Vieira, Escritório Saturnino de Brito e Luiz Camerlingo), os irmãos Moura Andrade não pouparam esforços para engendrar uma equipe que cuidasse do plano da cidade desde as construções civis até os aspectos técnicos, medicinais, paisagísticos etc.

Uma CN reveladora de ações envolvendo profissionais de áreas diversas a favor do urbanismo de qualidade. Um empreendimento que, nos anos 1930, já contava com o respaldo de um grupo multidisciplinar na confecção global da urbe. Um exemplo aqui exposto para direcionar nossa atenção ao quarto segmento do DNA das CNs: o profissional.

Toda CN deve apresentar, em sua concepção espacial, a participação de um profissional - ou de um grupo deles - responsável por desenhar o novo assentamento, seja seu traçado (vias, quadras e lotes), seja seu tecido (traçado e arquitetura), com menor ou maior grau de detalhamento: um envolvimento individual ou coletivo de projetistas detentores de um saber-fazer cidades, explanado a seguir por meio de exemplos retidos na história do urbanismo. 


\subsection{Os projetistas de cidades novas}

Além da figura do empreendedor, o projetista é uma personagem importante para o entendimento das origens e, particularmente, das características espaciais das CNs. Ao nos debruçarmos sobre a historiografia urbana, destacando dela a temática CNs, os estudos de caso abordados, geralmente os mais significativos, estão diretamente associados aos seus projetistas: Washington de L'Enfant, Canberra de Griffin, Chandigarh de Le Corbusier e Brasília de Lucio Costa. Uma insignificante amostra se considerarmos o universo real de CNs construídas. São centenas de exemplares não mencionados e ainda pouco estudados, cuja falta de conhecimento oculta o envolvimento de profissionais e suas respectivas formação, carreira e contribuição ao urbanismo: profissionais que não devem ser confundidos com mentores de cidades ideais.

Tratadistas e visionários, eles tiveram papel de destaque ao elaborar e propor novos tipos urbanos - teorizados, esquematizados, pormenorizados -, influenciando profissionais de diversas áreas na produção de espaços urbanos inéditos, implantados em diferentes momentos históricos. Contudo, dificilmente algum deles participou efetivamente no desenho de uma $\mathrm{CN}$ e, com isso, não pode ser identificado como projetista. Exemplo é o taquígrafo Ebenezer Howard (1850-1928), idealizador de uma cidade-modelo, que, pela falta de conhecimento técnico, delegou aos arquitetos ingleses Raymond Unwin (1863-1940) e Richard Barry Parker (1867-1947) a tarefa de traçar a primeira cidade-jardim: Letchworth, em 1903.

Portanto, os profissionais em questão são aqueles diretamente envolvidos na projetação de uma CN. Seja sobre uma folha de papel, seja sobre o sítio escolhido, o traçado da futura cidade, com maior ou menor detalhamento, surge pela mente do arquiteto, do planejador, do engenheiro civil, militar ou sanitário, do agrimensor, do topógrafo etc. Sozinhos ou em equipe, portadores de uma capacidade de desenvolver tal atividade, os projetistas traduzem nas CNs todo o 
conhecimento obtido em sua formação profissional e permeado pelas tendências ditadas pela cultura na qual vivem.

Da CN formatada sob a racionalidade filosófica na Antiguidade, passando pela CN enclausurada por fortificações militares na Idade Média e no Renascimento, pela CN embelezada aos moldes do barroco ou do Movimento City Beautiful, ${ }^{3}$ pela $\mathrm{CN}$ tecnicista para atender às necessidades do homem moderno, até chegar à CN democratizada em sua origem por políticas participativas, o que há são mudanças na configuração espacial geradas, segundo Claude Chaline (1985), por transições de diferentes profissões no comando projetivo das CNs ao longo da história.

Na Antiguidade, os pensamentos escritos por filósofos-arquitetos, como Aristóteles ${ }^{4}$ e Platão, que procuraram refletir as divisões lógicas e matemáticas numa sociedade ideal, influenciaram diretamente o teorizador, filósofo, matemático e arquiteto Hipódamo, nascido no século VI a.C., em Mileto. Hipódamo formulou os princípios básicos de urbanismo formal numa época em que essas noções não haviam ainda penetrado o terreno das realizações práticas. Embora o esquema geométrico - desenho formal, ortogonal ou em grelha - fizesse parte da realidade de culturas no Egito, na Mesopotâmia e na China há milênios, Hipódamo utilizou-o em sua prática urbanística - tradições geométricas e concepções aritméticas que “os

3 City Beautiful (cidade-monumento ou cidade monumental) foi um tipo urbanístico recorrente no início do século XX, utilizado, principalmente, por arquitetos norte-americanos, como Daniel Hudson Burnham (1846-1912). Essa tipologia urbanística, originária do urbanismo barroco e dos planos de L'Enfant para Washington e de Haussmann para Paris, apresentava como principal característica o redesenho do centro cívico das cidades, atribuindo-lhe um valor simbólico de poder. A valorização da figura pública perante a sociedade dar-se-ia mediante o traçado urbanístico geométrico e simétrico, a localização estratégica dos edifícios e monumentos e a arquitetura monumental dos edifícios públicos. Aplicada em cidades norte-americanas, como Chicago, Cleveland e São Francisco, essa tipologia também foi aplicada ou idealizada para inúmeras CNs capitais de colônias inglesas (Nova Délhi, na Índia; Canberra, na Austrália; e em inúmeras colônias no continente africano) e para as capitais de regime ditatorial, como Roma, de Mussolini; Berlim, de Hitler; e Moscou, de Stalin.

${ }^{4}$ Aristóteles escreve sobre urbanismo em sua Política, estabelecendo os três aspectos fundamentais da matéria sob os títulos de "higiene, defesa e circulação". Curiosamente, o filósofo já assinalava, na época, a incompatibilidade dos dois últimos, pois o plano irregular, como se demonstrou na Idade Média, é favorável à defesa, mas prejudicial ao fluxo. 
pitagóricos haviam transmitido do Oriente [...] e, especialmente, a veneração do número três” (PENNA, 1958, p. 42). Do mesmo modo, ele absorveu o "urbanismo prático” da Mesopotâmia, incorporando sistemas de infraestrutura - canalizações, esgoto, orientação e comunicações - em CNs por ele projetadas, como Mileto (reconstruída após ataque persa em 494 a.C.), Pireu (439 a.C.) e Rhodes (408 a.C.). Estas, bem como as demais cidades seguidoras da malha hipodâmica, apresentavam por características: traçados regulares, ortogonais, orientando a implantação dos edifícios; ágoras fechadas e portificadas; coordenação entre edifícios públicos para obter sentido de unidade urbanística; e terraplanagem em terraços e sítios acidentados, ligando desníveis mediante arquibancadas e escadarias (OLIVEIRA, 2007).

São as diretrizes verificadas no plano para Alexandria do século IV a.C., realizado pelos arquitetos Dinócrates de Rhodes e Soscrato de Cnido: uma cidade portuária organizada em uma malha quadriculada cardo-decumano cortada pela Canope avenida principal com cinco quilômetros de extensão e 30 metros de largura. No centro da urbe, à beira do porto, os arquitetos implantaram o palácio real, além de uma série de edifícios-monumentos, como teatro, biblioteca, museu, ginásio e o estádio.

Tipo semelhante de configuração urbana adotado por oficiais e agrimensores europeus - os lotisseurs - entre os séculos XIII e XV. O uso da quadra-tipo compondo uma malha cercada por muralhas, centrada por um espaço vazio (a praça) e limitada pela topografia do sítio escolhido é característica peculiar a qualquer $\mathrm{CN}$ desse período. Ou seja, um modo de fazer cidades que encontrou nos engenheiros-militares (italianos, alemães, espanhóis, franceses, portugueses etc.) o profissional responsável em projetar cidades após o século XV, especialmente as CNs de defesa, ocupação e expansão territorial.

Um dos expoentes dessa geração de projetistas foi o francês Sébastien Le Prestre (1633-1707), o marquês de Vauban. Durante o reinado de Luís XIV (16381715), Vauban trabalhou por 40 anos ao lado do Rei Sol como Comissário Geral das Fortificações, construindo um importante e vasto repertório sobre técnicas de ataque e defesa pelas fortalezas. 
Os 53 pequenos núcleos projetados em diferentes sítios foram "testemunhas do saber e do saber-fazer de um homem múltiplo: por vezes engenheiro, arquiteto e urbanista” (WARMOES; SANGER, 2007, p. 15, tradução nossa). ${ }^{5}$ As cidades de Vauban revelaram o seu rico conhecimento sobre técnicas militares, colocadas em prática nas fortificações impenetráveis. Distantes de simples cinturões envolvendo um núcleo urbano, as CNs de defesa do marquês surgiram protegidas por muralhas construídas a partir de estudos empíricos - envolvendo física, matemática e geografia - e implantadas após trabalhos topográficos, sobrepondo muros estelares rotacionados em diferentes patamares.

Esse conhecimento se tornou recorrente nos países europeus e exportado para territórios colonizados no novo continente. No Brasil, tal saber foi transmitido, destacadamente, a partir da fundação das Escolas Militares de Engenharia nas cidades de Salvador e Rio de Janeiro, no século XVIII. Nelas, foram introduzidos ensinamentos reguladores de arquitetura e urbanismo, permeados de conceitos renascentistas e barrocos, como: arquitetura com fachadas similares, traçado ortogonal para as vias urbanas, definição das dimensões e formas dos lotes (REIS FILHO, 1968). Os engenheiros militares eram tidos, entre outras coisas, como os “funcionários do urbanismo” português, responsáveis por “fazer cidades”. Suas ações eram direcionadas, mais especificamente, para levantamentos de campo e remodelações ou construções fortificadas novas, sob a forma de estrelas, abrigando, em seu interior, pequenos núcleos urbanos (BUENO, 2000). Contudo, o "saber fazer cidades” continuou no país sendo mais empírico que teórico.

Vilas e cidades eram projetadas por engenheiros e implantadas pelo "ruador" - que executava as ordens do engenheiro - em pontos até então isolados da nação, “subordinadas a um protótipo cujo traçado possuía conceitos barrocos (ruas retilíneas, praças bem delineadas, uniformidade de elementos arquitetônicos) facilmente

5 “[...] témoins du savoir et du savoir-faire d'un homme multiple: parfois ingénieur, architecte et urbaniste." 
adaptáveis às condições locais”, segundo afirmação de Roberta Marx Delson (apud FRIDMAN, 2005, p. 56).

A partir do século XVIII, com as especializações do conhecimento e a respectiva segmentação em diferentes ciências, as profissões passaram a ser determinadas pelas academias. Na pioneira França, surgem a École des Beaux-Arts (Escola de Belas Artes), a École des Ponts et Chaussées (Escola de Pontes e Caminhos) e a École Polytechnique (Escola de Engenharias), todas formadoras de profissionais aptos a exercerem a função de projetista (CLAVAL, 2001). Todavia, cada qual tinha enfoques específicos sobre as questões urbanas - fosse pela composição estética, fosse por aspectos práticos, como infraestrutura -, fomentando, com isso, a diversidade de exemplares e tipos de cidades criadas.

Nos Estados Unidos da América, as Schools of Landscape Architecture and City Planning (Escolas de Paisagismo e Planejamento Urbano) diplomaram arquitetos-paisagistas que ditaram o modo de projetar cidades em fins do século XIX e início do século XX. Warren Henry Manning (1860-1938), empregado do renomado paisagista Frederic Law Olmsted (1822-1903) entre 1888 e 1896, projetou a CN de Gwinn (Michigan) em 1906 - comunidade planejada para a firma Marquette Iron Range -, com a preocupação em adequar o plano urbanístico às condições oferecidas pelo sítio. Elbert Peets (18861968) planejou, durante o New Deal, a cidade de Greendale (Wisconsin) - núcleo urbano com 3 mil moradias para 12 mil habitantes -, preservando antigas casas rurais do sítio e ligando centro da cidade e cinturão verde por meio de caminhos de pedestres. Anos antes, Peets já havia projetado outra CN, Kohler (Wisconsin), na companhia do planejador alemão Werner Hegemann (1881-1936), ${ }^{6}$ de quem foi assistente. Na lista, acrescenta-se John Nolen (1869-1937), o primeiro americano a se identificar como city planner, proprietário de um escritório responsável pelo desenvolvimento de “mais de

6 Peets e Hegemann escrevem juntos o livro The American Vitruvius: an architect's handbook of civic art, publicado em 1922. Um verdadeiro atlas ilustrativo no qual os autores trabalham temas como: resgate da arte cívica iniciado por Camillo Sitte (1843-1903), desenho de praças e espaços públicos em cidades europeias, agrupamento de edifícios, composição de vias, paisagismo de parques, planejamento urbano como desenho totalitário, finalizando a obra com uma análise do plano urbanístico da capital Washington. Um referencial projetivo para inúmeros profissionais. 
400 planos para CNs” (MARTIN, 1999, p. 69), dentre eles a CN de Madison (Wisconsin), parcialmente construída em 1907.

Figura 13: Neuf Bisach

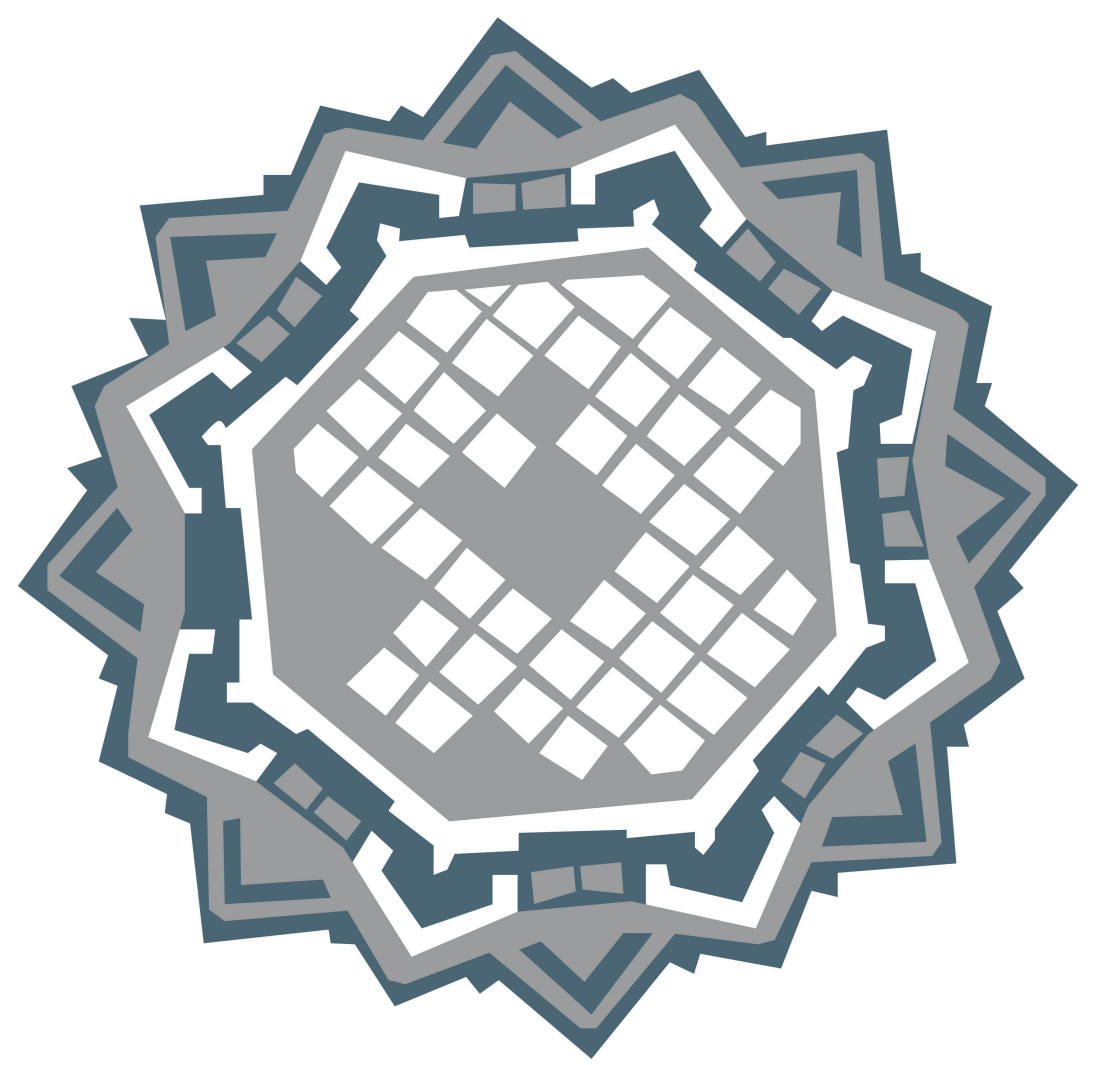


De volta ao velho continente, a cidade como espaço cênico era trabalhada por arquitetos formados na École des Beaux-Arts de Paris. Exemplo disso foi a "Cidade Mundial”, projetada pelo arquiteto francês Ernest M. Hébrard (1866-1933) em 1912. Um empreendimento encomendado por Henrik Christian Anderson, um rico escultor norte-americano que visionava criar uma cidade para a paz mundial. Diferentemente de uma cidade-modelo, tal como a cidade-jardim (um protótipo destinado a ser reproduzido), essa cidade seria uma verdadeira capital mundial, reunindo sua elite em uma cidade única, prevista para ser implantada ao lado de Bruxelas (Bélgica).

Seu plano constava de eixos simétricos e uma longa perspectiva central. Os três nós urbanos sucessivos da cidade seriam uma área destinada aos Jogos Olímpicos, um complexo de artes e um centro de comunicações construído ao redor da monumental Torre do Progresso, de onde jornalistas do mundo inteiro divulgariam as novas descobertas da ciência assim como os avanços morais e artísticos da sociedade. Como discípulo da Beaux-Arts, Hébrard se preocupou com o sistema de trânsito, hierarquizando a trama de vias arborizadas com avenidas, ruas e rotatórias para organizar o tráfego, largas calçadas e áreas de estacionamento, canais para navegação e transportes subterrâneos. Também se preocupou com questões higienistas ao adotar inúmeros pequenos parques e abundância de luminosidade.

Foi uma visão artística sobre a cidade que começou a perder campo frente a um urbanismo funcionalista e tecnicista adotado por arquitetos e engenheiros, mesmo por aqueles formados na Beaux-Arts de Paris, como Tony Garnier (18691948). A partir de um trabalho de graduação, Garnier projetou, entre 1901 e 1904, a cité industrielle (cidade industrial), que se tornou pública apenas em 1917, com a edição de sua obra Une cité industrielle étude pour la construction des villes. O trabalho apresentava gravuras do projeto da cidade industrial e sintetizava os principais elementos que deveriam constituir a cidade: administração e estabelecimentos públicos, escolas, estabelecimentos sanitários, estação ferroviária, fábrica e hidrelétrica (todos projetados em concreto armado). Incorporando instrumentos de zoneamento, saneamento, edificação, uso social do solo urbano, entre outros, o 
projeto de Garnier refletia a evolução pela qual a escola urbanística passava naquela época - uma intensa produção de tipos de novas cidades, que tinha por objetivo principal melhorar as condições de vida urbana pelo conhecimento técnico-científico.

No Brasil, nesse momento, os profissionais encarregados de projetar cidades formavam-se ou na Escola de Belas Artes do Rio de Janeiro ou em Escolas Politécnicas, como a de São Paulo. Aberta em 1894, a Politécnica de São Paulo inovou o ensino de engenharia e arquitetura no Brasil. Diferentemente das Escolas do Rio e da Bahia - onde o ensino fundamental se dava na Politécnica e os específicos eram divididos entre as Escolas de Minas e Pontes ou Belas Artes, para os futuros profissionais que desejavam a arquitetura -, essa instituição se espelhou nas escolas de Zurique e Karlsruhe (Alemanha), unificando o ensino do curso fundamental e dos cursos especiais em uma única escola (FICHER, 2005). Aproximando as diversas ciências, possibilitando uma integração entre as áreas e a construção de um pensamento globalizante, o modelo visava a formar profissionais, engenheiros-arquitetos, aptos a responder às necessidades apresentadas pela cidade de sua época, como coloca Sylvia Ficher em seu livro Os arquitetos da Poli: ensino e profissão em São Paulo:

[...] o curso de arquitetura da Politécnica visava formar engenheiros-arquitetos preparados para projetar e construir edificações, em contraste com seus colegas engenheiros civis, que deveriam projetar e construir obras de engenharia: pontes, viadutos, portos, canais, estradas de ferro e de rodagem, redes de água e esgoto etc. [...] divisão era razoavelmente clara no que dizia respeito ao ensino. (FICHER, 2005, p. 26). 
Pois, na prática, mesmo alguns engenheiros-arquitetos formados na Poli se especializaram em questões urbanas, ${ }^{7}$ como Luís Inácio de Anhaia Melo (18911974) e Francisco Prestes Maia (1896-1965), responsável pelo projeto da CN de Panorama, em 1946, no interior de São Paulo.

Paralelamente ao trabalho volumoso de engenheiros e arquitetos, temos conhecimento de outros profissionais que também atuaram no campo do urbanismo, formados em engenharia sanitária, engenharia agrônoma e mesmo em cursos técnicos para agrimensores-topógrafos. Saturnino de Brito (1864-1929), responsável pela expansão de Santos e dezenas de planos de reestruturação urbana país afora, era sanitarista. Bernardo Sayão Carvalho de Araújo (1901-1959), “plantador de cidades e estradas”, dentre elas a CN de Ceres (GO) e a rodovia Belém-Brasília, era engenheiro agrônomo. Germano Robach (ignoto-ignoto), autor da demarcação da CN de Cosmorama junto à ferrovia Araraquarense (SP) em 1931, era agrimensor.

Porém, se a figura de um profissional isolado, ou destacado, na projetação de CNs era evidente até a primeira metade do século XX, após a Segunda Guerra Mundial essa posição passou a ser dividida com equipes multidisciplinares tanto no exterior como no Brasil. Arquitetos, engenheiros, agrimensores, topógrafos foram contratados para compor, juntamente com outros profissionais - geógrafos, psicólogos, economistas, sociólogos, antropólogos, historiadores etc. -, grupos que iriam planejar e desenhar novos núcleos urbanos. Françoise Choay, em artigo sobre as villes nouvelles, certifica tal transformação nos anos 1960, quando sua realização foi apoiada por pesquisas e estudos das ciências sociais (CHOAY, 1988). Planejadores e arquitetos descobriram a panaceia das equipes pluridisciplinares; psicólogos e sociólogos produziam, com agitação, problemas, soluções e a terminologia adequada.

7 Podemos averiguar um aumento das questões urbanísticas na formação de engenheiros-arquitetos com a matriz em vigor nos anos de 1926 a 1931, quando o urbanismo "era coberto por um programa detalhado, tratando, entre outros aspectos, de: urbanização, a cidade como um problema de governo, a legislação urbanística moderna, a rua, a circulação, os centros urbanos e as praças, os quarteirões, os bairros e sua especialização (zoning), as cidades-jardim, os planos regionais e nacionais, a maioria desses temas exemplificada pela experiência inglesa e americana” (FICHER, 2005, p. 199). 
Grande parte dessas equipes era ligada a órgãos públicos, escolhida para concretizar políticas de controle de expansão urbana, de ocupação territorial e de desenvolvimento econômico.

Na URSS, como já citado, havia o Comitê do Estado para Construção Civil e Arquitetura (Gosgrajdanstroi), responsável pela política de urbanismo, com 18 órgãos assistentes e um total de 200 mil pessoas trabalhando com questões urbanas (MERLIN, 1975). No Japão, as CNs de Tama (1965) e Tsukuda (2000) ficaram sob os cuidados da Corporação de Desenvolvimento Habitacional e Urbano (DUCON; YOKOHARI, 2006). Na Suécia, planejadores regionais construíram uma extensiva rede ferroviária ligando as cidades-satélites com o centro de Estocolmo, comandados pelo arquiteto Sven Markelius na década de 1950 (CERVEO, 1995). Na Índia, a maior parte das CNs foi concebida por planejadores e construída por autoridades de setores do desenvolvimento (PRAKASH, 1969). Na Venezuela, os projetos de algumas CNs foram desenvolvidos pelo órgão público Corporación Venezoelana de Guayana com o auxílio de equipes vindas do Instituto de Tecnologia de Massachusetts (MIT) e da Universidade de Harvard, ambas instituições norte-americanas (TURNER; SMULIAN, 1974). Na Argélia, a CN de Ali Mendjeli apresentou dois projetos: um de 1974, confeccionado pelo governo argelino com seu Escritório de Estudos Nacionais (CADAT) e auxiliado por técnicos tchecos; outro de 1990, realizado pelo Centro de Estudos e de Realizações em Urbanismo (URBACO), um órgão estatal (CHERRAD apud BOUMAZA et al., 2006). Mesmo nos EUA, onde as CNs ficaram a cargo de empreendimentos privados, os projetos foram realizados por equipes de profissionais de diversas áreas, como na CN de Columbia (1963), cujo fundador, James W. Rouse, reuniu uma equipe de 18 profissionais (LACONTE et al.; 1982). No Brasil, além dos exemplos de CNs de realocação, nas quais a participação de equipes multidisciplinares foi recorrente, temos a CN de Dassópolis - núcleo urbano não executado para 2,5 mil habitantes e com função de colonizar a Amazônia -, elaborada por 
uma equipe de professores e pesquisadores da Universidade Estadual de Campinas (Unicamp) na década de 1980 para o Projeto Cotrijuí-Norte.

Quando não havia a presença de tais instituições públicas, escritórios privados de arquitetura e planejamento urbano eram convidados pelo próprio Estado ou participavam de concursos públicos destinados a projetos de CNs.

Na China, o Escritório de Administração em Planejamento Urbano de Xangai realizou um concurso internacional para contratação de empresas estrangeiras, visando ao planejamento de dez CNs (MING, 2003). Dentre elas, estão: Nanhui, desenhada pelo escritório francês Arte-Charpentier (do arquiteto Pierre Clement) no início dos anos 1990; Nan Cha, realizada por Campenon Bernard S.G.E. e pelo escritório de arquitetura de Ricardo Bofill em 1993; e Tianjin Commercial Development Area (TEDA), com projeto inicial canadense em 2001.

Ainda na Ásia, o mesmo procedimento foi adotado na Indonésia, com a CN de Bekasi, elaborada por arquitetos franceses em 1982. Na Tailândia, com a CN de Muang Thong Tani, de concepção australiana e realização francesa (Bouygues Société), entre 1990 e 1995. E na Malásia, com a CN administrativa de Putrajaya, projeto dos franceses Dubus e Richez, em fins dos anos 1990 (PETIT, 2002).

Outros escritórios também trabalharam na concepção de CNs. O escritório grego Doxiadis Associates trabalhou no plano das CNs de Islamabad (capital do Paquistão), Surchinar (CN industrial no Iraque), Kafue (Zâmbia) e Tema (Gana). O escritório de arquitetura francês Kalt, Pouradier Duteil et Vignal projetou Malbaza (Nigéria). O grupo formado pelos urbanistas M. P. Bredsdorff, S. E. Rasmussen e M. R. Drayby desenhou a cidade-satélite dinamarquesa de Albertslund. E mesmo um projetista de campos de golfe, Jack Nicklaus, foi contratado para traçar a CN de Bumi Serpong Damai, na Indonésia (FIRMAN, 2004).

Na França, as villes nouvelles foram envoltas por uma rica e densa equipe de profissionais, desde seu planejamento original até o desenho dos edifícios de cada cidade. Na fase inicial, Paul Delouvrier, encarregado de implantar as CNs francesas, foi auxiliado por: Jean Millier (autor da CN de Abidjan, na Costa do 
Marfim); Jacques Michel (politécnico envolvido no Plano de Melhoramento de Paris, de 1960); Serge Goldberg (estudioso do urbanismo norte-americano e especialista em redes rodoviárias); Michel Piquart (idealizador do plano urbanístico de Constantine); e Jean Vaujour (prefeito e conhecedor das coletividades da periferia de Paris) (TILLIETTE, 1985). Eram altos funcionários, unidos a engenheiros, arquitetos, economistas, geógrafos, sociólogos e estagiários universitários, contratados para elaborar os projetos, separados em dois ramos de atuação: urbanismo de estudos (mais arquitetos) e urbanismo operacional (fase de dependência mútua).

Reunidos em Établissements publics d'aménagement des villes nouvelles françaises (EPA), os primeiros trabalhos foram organizados no Esquema Diretor de Estruturas (1965-1968), que definiu o programa e a parte de planejamento e organização do espaço de cada CN. Em Cergy-Pontoise, por exemplo, o processo projetivo ocorreu a partir de células. Cada célula trabalhava com uma área específica e continha um engenheiro, um arquiteto e um desenhista. Essas células se ocupavam da concepção dos bairros, do urbanismo operacional, do planejamento dos espaços públicos, da arquitetura, das diretrizes operacionais, da assistência aos construtores etc. Havia também equipes formadas por um arquiteto, um engenheiro, um paisagista e um sociólogo. Nos anos 1980, a equipe multidisciplinar foi substituída pela figura do planejador, que assumiu uma visão global para sua função: de urbanista, técnico, comercial, financeiro e publicitário (CLAUDE, 2005).

Concomitantemente, diversos concursos foram realizados pelo EPA. Cada concurso compreendia três escalas de intervenções: 1) grandes concursos de urbanismo (arquitetura e organização urbana de áreas de 700 a 7 mil moradias); 2) concursos para habitação (mais recorrente, de 70 a algumas centenas de moradias); e 3) concursos de espaços públicos. Desses, seis concursos foram efetuados para o primeiro grupo, 32 concursos para o segundo grupo e 45 concursos para o terceiro grupo. Com isso, previa-se atribuir às CNs um caráter de novidade, 
associado a um caráter experimental - integração de funções urbanas e arquitetura de qualidade. Ao todo, 260 arquitetos ou agências trabalharam nos projetos, o que garantiu a cada CN uma diversidade arquitetônica (FRANCE, 1980).

Tal fato pode ser comprovado, atualmente, nas villes nouvelles, que se transformaram em roteiro turístico tanto para leigos como para profissionais da área, pelas “soluções espaciais miraculosas” adotadas (WERMES, 1991, p. 21, tradução nossa). ${ }^{8}$ Uma diversidade de arquitetura contemporânea, como: as “Arcadas do lago” de Ricardo Bofill (1939-); as escolas de Stanislaw Fiszer (1935-); as moradias de Alain Sarfati (1937-); o “Castelo d’água” de Christian de Portzamparc (1944-); e o eixo monumental do artista e escultor Dani Karavan (1930-) para Cergy-Pontoise.

De fato, as CNs francesas se tornaram um campo de trabalho para arquitetos-paisagistas assim como para recém-formados e outros profissionais (YOUNGMAN, 1998). Algo repetido não apenas na Europa como em outros continentes até os dias atuais.

No decorrer da história, vimos, portanto, o envolvimento de diferentes projetistas na criação de CNs. Foram filósofos, arquitetos, loteadores, planejadores, engenheiros militares, sanitaristas, civis, agrônomos, técnicos agrimensores, topógrafos, planejadores e artistas. Um leque de denominações distintas para definir o mesmo profissional: o urbanista.

Especialista em conceber o espaço urbano, em planejar as cidades, ele é o responsável por distribuir sobre "um solo vasto e parcimonioso as funções múltiplas” de uma cidade (DELOUVRIER apud TILLIETTE, 1985, p. 13, tradução nossa). ${ }^{9}$ Seja ela espontânea ou intencionalmente criada, toda cidade irá ter, em determinado momento, a contribuição desse profissional no gerenciamento de seu espaço físico a fim de qualificá-lo para seus habitantes.

Nas CNs, a participação de um urbanista é visível desde sua concepção. Após a decisão do empreendedor em criar uma urbe para um fim específico, tendo

"[...] solutions spatiales miraculeuses [...]"

9 "[...] un terrain vaste et parcimonieux aux multiples fonctions." 
condições propícias para sua construção, o urbanista entra em cena para tornar a cidade imaterial em cidade palpável. A partir do repertório, do conhecimento e da cultura que envolve essa personagem, a linha teórica seguida, o tipo adotado e o espaço urbano projetado tomam corpo sob a forma de uma cidade. Projetista e projeto ficam, assim, unidos na história de cada CN. 